UNIVERSITY OF COPENHAGEN

\title{
Introduction to Forest Genetics
}

Wellendorf, Hubert

Publication date:

1992

Document version

Publisher's PDF, also known as Version of record

Citation for published version (APA):

Wellendorf, H. (1992). Introduction to Forest Genetics. Danida Forest Seed Centre. Lecture Note D-2 
Titel

Introduction to Forest Genetics

\section{Authors}

Hubert Wellendorf and Bjerne Ditlevsen

\section{Publisher}

Danida Forest Seed Centre

Series - title and no.

Lecture Note D-2

\section{DTP}

Melita Jørgensen

\section{Citation}

Wellendorf H. and B. Ditlevsen. August 1992. Introduction to Forest

Genetics. Lecture Note D-2. Danida Forest Seed Centre, Humlebaek, Denmark.

\section{Citation allowed with clear source indication}

Written permission is required if you wish to use Forest \& Landscape's name and/or any part of this report for sales and advertising purposes.

The report is available free of charge

SL-International@kvl.dk

\section{Electronic Version}

www.SL.kvl.dk 


\section{CONTENTS}

The Hardy-Weinberg Equilibrium

Deviations from the Hardy-Weinberg Equilibrium

Selection

Non-random mating, small populations, and inbreeding

Migration

4. QUANTITATIVE GENETICS

6

Metric Characters 



\section{INTRODUCTION}

Forest genetics concerns application of general genetic principles in management of forest resources.

Specific examples of application are natural or artificial regeneration, seed production, seed transfer, gene conservation, tree improvement, and tree breeding.

Among the multiple disciplines of modern genetics, population genetics and quantitative genetics are considered the more important areas for forestry.

Population genetics is important because this field concerns the genetic principles of whole populations rather than the individual tree, and because it has developed models about whole populations of natural or not yet fully domesticated organisms.

Quantitative genetics is important because most characters that we are studying in trees are quantitative, influenced by multiple genes as well as by the environments. Typical examples are yield of timber, fruits or whatever other products we want to harvest from our trees.

Both population and quantitative genetics rely firmly on basic Mendelian genetics. The cytological mechanism of inheritance is described in Lecture Note A-3, Natural Variation as a basis for Tree Improvement.

\section{MAIN PRINCIPLES OF MENDELIAN GENETICS}

According to Mendelian genetics, normal diploid individuals have two sets of genes, one set received from the mother and one set from the father. These genes (synonym alleles) are physically arranged on strings (chromosomes) in the nucleus of each cell. During normal (somatic) growth, mitotic cell divisions split each chromosomes with its complement of alleles into two identical parts each of which goes to the two new cells - and thereby keeping each cell of a given individual with the same double complement of chromosomes and alleles $-2 \mathrm{n}$ (diploids).

Prior to normal sexual reproduction, egg and sperm cells are formed by a special series of cell divisions (meiosis), in which the complement of alleles and chromosomes are reduced from two sets to one set. Cells at this stage is said to be haploids (n), i. e. each gene and chromosome is now only represented by one example. Because of the complicated meiotic divisions (particularly the crossingover mechanism) the alleles in the sexual cells are a mixture of those received from the father and those received from the mother. Not two sexual cells are identical in wild cross-breeding organisms. 
During fertilization, two haploid cells (gametes) unite to create a new diploid cell of unic composition. This cell develops itself into an embryo and further into an individual by mitotic divisions.

For many forest trees, a vast surplus production of pollen and seed takes place, which means that only a small fraction of the produced cells develop into breeding individuals.

\section{POPULATION GENETICS}

The following presentation is mainly extracted from Falconer (1981).

Let us look at a random gene locus, i.e. a position on the chromosome where a special gene or allele is found.

The locus is called $\mathrm{A}$, and the two alleles present in a diploid organism are called $A_{1}$ and $A_{2}$. Among diploid organisms there are now three possible genotypes: one organism may have $A_{1}$ or $A_{2}$ in both relevant chromosomes $\left(A_{1} A_{1}\right.$ or $\left.A_{2} A_{2}\right)$, or it may have $A_{1}$ in one chromosome and $A_{2}$ in the other $\left(A_{1} A_{2}\right)$.

\begin{tabular}{ll}
\hline genotypes & \multicolumn{1}{c}{ designation } \\
\hline$A_{1} A_{1}$ & homozogyte $A_{1}$ \\
$A_{1} A_{2}$ & heterozygote \\
$A_{2} A_{2}$ & homozygote $A_{2}$
\end{tabular}

The frequency of genes (alleles) and genotypes in the actual population can be recorded.

The population is considered as a breeding group, i.e. matings occur and new generations evolve. We will look at the transmission of genes from one generation to the next.

\section{The Hardy-Weinberg Equilibrium}

This law describes what happens with the alleles in our (above-mentioned) locus A during a generation turn-over in the breeding population during well-defined simplified conditions.

The law tells us that in large, random-mating populations with no selection, mutation or migration, the gene- frequencies and the genotype frequencies are constant from generation to generation, see page 5 . 
In the parent population, the male population and the female population contain the alleles $A_{1}$ and $A_{2}$. The frequency of $A_{1}$ is called $p$ and that of $A_{2}$ is called q.

\begin{tabular}{|c|c|c|c|c|c|}
\hline \multirow{3}{*}{$\begin{array}{l}\text { Parent } \\
\text { population }\end{array}$} & & & \multicolumn{2}{|c|}{ males } & \\
\hline & \multicolumn{2}{|c|}{$\begin{array}{c}\text { genes } \\
\text { (alleles) }\end{array}$} & $A_{1}$ & $A_{2}$ & \\
\hline & & frequencies & $\mathrm{p}$ & $\mathrm{p}$ & $p+q=1$ \\
\hline \multirow{2}{*}{ females } & $A_{1}$ & $\mathrm{p}$ & $A_{1} A_{1}$ & $\begin{array}{c}A_{1} A_{2} \\
p q\end{array}$ & \multirow{2}{*}{$\begin{array}{c}\text { offspring } \\
\text { population }\end{array}$} \\
\hline & $\mathrm{A}_{2}$ & $q$ & $\begin{array}{c}A_{1} A_{2} \\
p q\end{array}$ & $\begin{array}{c}\mathrm{A}_{2} \mathrm{~A}_{2} \\
\mathrm{q}^{2}\end{array}$ & \\
\hline
\end{tabular}

Summary of offspring population:

genotypes

$A_{1} A_{1}$ occurs with a frequency of $p^{2}$

$A_{1} A_{2}$ occurs with a frequency of $2 p q$

$A_{2} A_{2}$ occurs with a frequency of $q^{2}$

$\begin{array}{lll}\text { genes } & A_{1} & \text { occurs with a frequency of } p^{2}+p q=p(p+q)=p \\ \text { (alleles) } & A_{2} & \text { occurs with a frequency of } q^{2}+p q=q(q+p)=q\end{array}$

The tables show that in the offspring population the frequencies of genes (alleles) are the same as in the parent generation.

Furthermore, it shows the expected frequencies of genotypes in any one of the generations. 


\section{Deviations from the Hardy-Weinberg Equilibrium}

A major field of interest in forest genetics is to study deviations from the simplified conditions behind the Hardy-Weinberg equilibrium.

Why?

Because important deviations may result in changes of gene and/or genotype frequencies.

Changes in genotype frequencies may change the behaviour of the tree populations in a favourable or unfavourable direction. The ambition is, by a sound insight in population genetics, to predict and eventually utilize these changes to the benefit of the tree grower and the subsequent utilization.

\section{Selection}

One obvious deviation from the cited simplified conditions is selection. In fact, the whole business of tree breeding is based on the assumption that we, by selecting only the very best individuals and crossing them together, are able to change the gene and genotype frequencies concerning the genes that influence a particular character, for instance growth rate. If we are successful in this, i.e. if we obtain a detectable gain in the offspring from the selected trees compared to the base population, it can only be explained by a change in gene or genotype frequencies.

\section{Non-random mating, small populations and inbreeding}

Other simplified conditions for the Hardy-Weinberg equilibrium to be valid are that the population is large and members are mating at random.

Typical deviations from these conditions in forest stands are that

1) only a restricted number of trees are flowering and setting fruit or seed

2) after a number of cycles of natural regeneration, neighbouring trees tend to be related because most fruits fall and establish themselves in the neighbourhood of the mother tree. Furthermore, pollen may be scarce and not travelling far. The resultant effect is that the population is split into a number of sub-populations and that gene frequencies fluctuate randomly between these sub-populations or neighbourhoods.

Such processes may have the following practical effects:

a) the performance of progenies originating from different neighbourhoods within one particular stand may vary from each other (random drift of gene frequencies) 
b) general inbreeding may develop within each neighbourhood leading to reduced growth rate and survival of the offspring (inbreeding depression).

It can be shown that inbreeding leads to an excess of homozygotes and this excess is dependant on a factor, $\mathrm{F}$, called the inbreeding coefficient.

\begin{tabular}{|c|c|c|}
\hline \multirow[t]{2}{*}{ genotypes } & \multicolumn{2}{|c|}{ frequencies } \\
\hline & $\begin{array}{l}\text { under H.-W } \\
\text { conditions }\end{array}$ & $\begin{array}{c}\text { after } \\
\text { inbreeding }\end{array}$ \\
\hline$A_{1} A_{1}$ & $p^{2}$ & $p^{2}+p q F$ \\
\hline$A_{1} A_{2}$ & $2 p q$ & $2 p q+2 p q F$ \\
\hline$A_{2} A_{2}$ & $q^{2}$ & $q^{2}+p q F$ \\
\hline
\end{tabular}

If we are able to observe individual genotypes for a number of characteristic marker genes in tree breeding populations, it is possible to estimate the inbreeding coefficient according to the formulas in the table above. Such marker genes are available in a number of tree species as biochemical markers, typically isoenzymes.

The occurrence of inbreeding is important in practical forestry as it has been detected for a number of tree species, as well as for other organisms, that growth rate is linear dependant on the inbreeding coefficient $\mathrm{F}$, at least in the F-range from 0 (no inbreeding) to 0.5 .

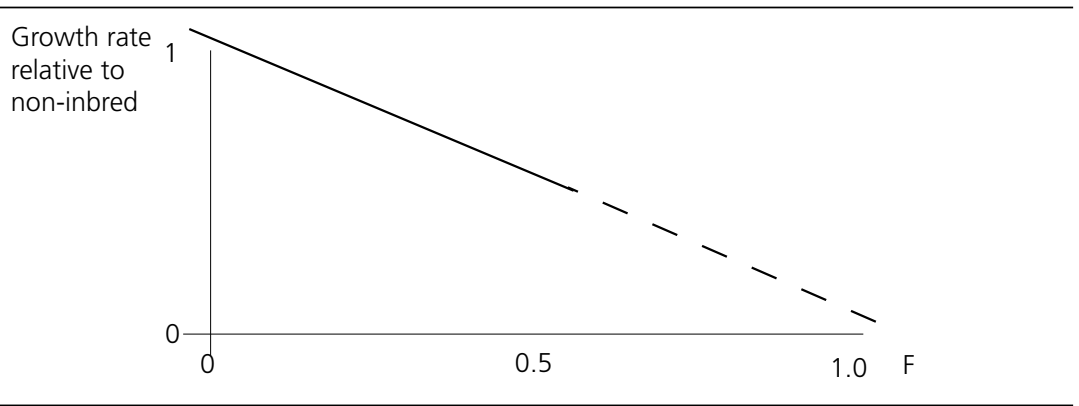

Figure 1. Effect of the inbreeding coefficient ö̈ growth."

Care should be taken in seed procurement as well as in breeding programmes to be aware of the problem of small populations and subsequent random drift and inbreeding in following generations.

\section{Migration}

For some species, seed and especially pollen can blow over long distances. For such species, the above-mentioned small neighbourhoods may not be so important, but the problem of immigrating genes from more or less distant stands may change the gene frequencies of the offspring compared to the parent generation.

The practical result may be unpredictable performance of the offspring of a seed stand with a favourable phenotype (apparent value).

We are saying that the seed source is poorly isolated from contaminating pollen sources. 


\section{QUANTITATIVE GENETICS}

\section{Metric Characters}

Most characters that we can detect in our trees are quantitative or metric. Examples are growth rate, density of wood, and amount of seed or fruit production.

These characters are influenced by genetics as well as environment and the developmental stage of the tree.

The genetic component is typically polygenic, which means that not only one gene locus influences the expression of the character but a whole array of genes (alleles) distributed to many loci on the chromosomes are responsible.

\section{Phenotype, Genotype, Breeding Value, and Heritability}

For each character, the observed phenotypic or apparent value of a tree as a member of a population is composed of two components

a) a genetic component, $G$

b) an environmental deviation, $\mathrm{E}$

so

$$
P=G+E
$$

For the whole population under study,

$$
\mathrm{M}_{\mathrm{E}}=0 \text {, so } \mathrm{M}_{\mathrm{P}}=\mathrm{M}_{\mathrm{G}}
$$

$\mathrm{M}=$ Mean

When a given population of trees in a delineated environment is considered, members of the population are assumed to interbreed freely at random. For that reason the size of a well-defined population of trees may not be too large.

For each character we can continue with the following expressions:

$$
\begin{aligned}
& \frac{\text { values }}{\mathrm{P}=\mathrm{G}+\mathrm{E}} \quad \frac{\text { variances }}{\mathrm{V}_{\mathrm{P}}=\mathrm{V}_{\mathrm{G}}+\mathrm{V}_{\mathrm{E}}} \\
& h_{B S}^{2}=\frac{V_{G}}{V_{P}}=\frac{V_{G}}{V_{G}+V_{E}}
\end{aligned}
$$

where

P: phenotypic value, i.e. the apparent, observable value of for instance tree height

G: genotypic value (hypothetical) 
E: environmental deviation (hypothetical)

$\mathrm{V}_{\mathrm{P}}$ : phenotypic variance between individuals within the population; the apparent, observable variation

$\mathrm{V}_{\mathrm{G}}$ : genetic variance component caused by genetic variation (hypothetical)

$\mathrm{V}_{\mathrm{E}}$ : environmental variance component caused by environmental variation (hypothetical)

$\mathrm{h}_{\mathrm{BS}}^{2}$ : broad-sense heritability, the proportion of the phenotypic variance caused by genetics (hypothetical).

The genetic component, G, can further be split into two components, A and D. Which means that

$$
\begin{aligned}
& \text { values } \\
& \text { variances } \\
& P=G+E \\
& \mathrm{~V}_{\mathrm{P}}=\mathrm{V}_{\mathrm{G}}+\mathrm{V}_{\mathrm{E}} \\
& =\mathrm{A}+\mathrm{D}+\mathrm{E} \\
& =\mathrm{V}_{\mathrm{A}}+\mathrm{V}_{\mathrm{D}}+\mathrm{V}_{\mathrm{E}} \\
& h^{2}{ }_{N S}=\frac{V_{A}}{V_{P}}=\frac{V_{A}}{V_{A}+V_{D}+V_{E}}
\end{aligned}
$$

where

A: breeding value, the fraction of the genetic value which can be transferred directly from parents to offspring *)

D: dominance deviation, the fraction of the genetic value that are caused by dominance between alleles within loci, i.e. non-additive gene effects

$\mathrm{V}_{\mathrm{A}}$ : variance in breeding values between individuals within the population

$\mathrm{V}_{\mathrm{D}}$ : variance in dominance deviations between individuals within the population

$\mathrm{h}^{2}{ }_{\mathrm{NS}}$ : narrow-sense heritability, the proportion of the phenotypic variance caused by variation in breeding value between individuals. 
The meaning of the narrow-sense heritability, $\mathrm{h}^{2}{ }_{\mathrm{NS}}$, can also be expressed as the slope of the parent-offspring regression:

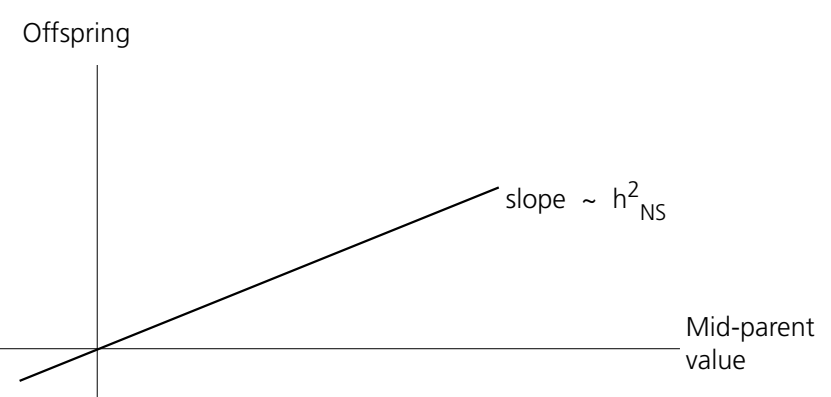

Figure 2. Heritabilty as parent-offspring regression. Mid-parent value is the average phenotypic value of the two parents.

If each female is mated to a random set of males, it can be shown that the slope of the female parent-offspring regression can be estimated to

$$
1 / 2 \times \mathrm{h}^{2}{ }_{\mathrm{NS}}
$$

Open-pollinated offspring from individual trees within a stand may simulate this situation, provided random mating among members of the population.

Finally, heritability can be interpreted as the regression between phenotype and genotype (broad-sense heritability) and between phenotype and breeding value (narrow-sense heritability).

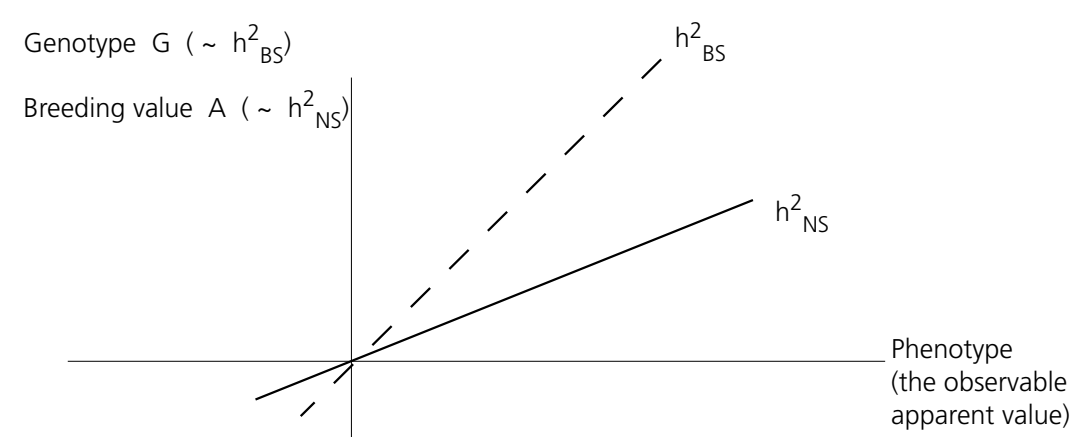

Figure 3. Heritability as regression of genotype on phenotype. 


\section{PRACTICAL APPLICATIONS}

In any tree-improvement programme some sort of selection is applied with the expectation that a genetic gain is achieved. The heritability concept described above for individual selection of parents can be extended to the provenance mean level, i.e. we can set up a general genetic response formula

$$
\mathrm{R}=\mathrm{h}^{2} \times \mathrm{D}
$$

where

$\mathrm{R}$ : Genetic response after one generation of selection

$\mathrm{h}^{2}$ : Heritability for the character under consideration

D: Selection differential (see figure 4), i.e. the phenotypic difference between the selected individuals (or provenances) and the population mean.

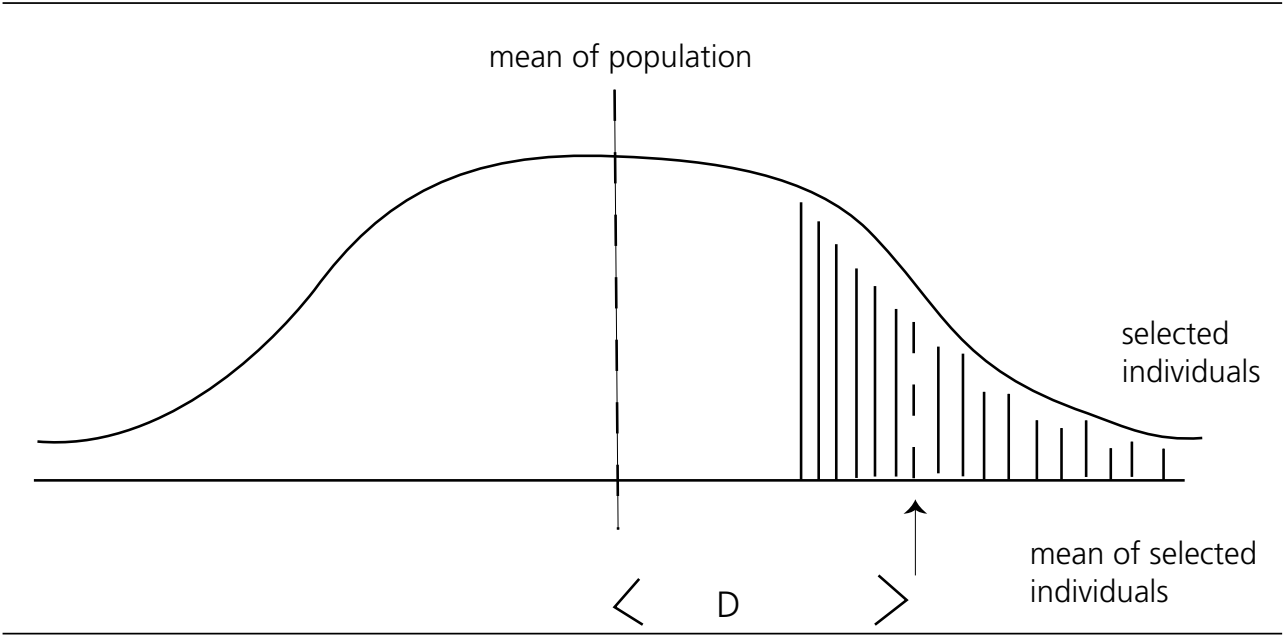

Figure 4. Selection differential. Mean of selected individuals minus population mean.

\section{Example 1}

A provenance test of 25 provenances in a given environment has shown

1) a provenance-mean heritability of 0.7

2) the best three provenances are yielding $15 \%$ more than the local seed source in general use. The local seed source is close to the experimental grand mean.

By selecting the 3 highest-yielding provenances as seed sources for future afforestation, a genetic response of

$$
\begin{aligned}
\mathrm{R} & =\mathrm{h}^{2} \times \mathrm{D} \\
& =0.7 \times 15 \%=10.5 \%
\end{aligned}
$$

should be expected, provided 
a) these seed sources are available

b) the experimental site is representative of the afforestation sites

c) the experiment is evaluated at a late stage in the rotation *)

d) no unforeseen adaptational problems develop.

\section{Example 2}

An early progeny test of 25 open-pollinated plus-trees selected in a given stand of the local landrace is available. A general stand collection from many random trees from the same stand is included in the field trial to represent the base population. A clonal seed orchard has been established with clones of the 25 plus trees.

By applying the above described quantitative genetic methods on such a material, it is possible to obtain

1) local estimates of genetic gain by the applied plus-tree selection realized by the offspring of a clonal seed orchard

2) estimates of individual variation in breeding values between plus-trees; based on these breeding-values, narrow-sense heritabilities can be estimated too.

Such genetic parameters for a number of potential breeding objectives (e.g. health, growth, and quality) are important for the planning of future breeding strategies to give an indication of possible gain.

\section{REFERENCES}

Falconer, D.S. 1981

Introduction to Quantitative Genetics, The Ronald Press Company, New York. 